\title{
Tracheostomy in patients with acute respiratory distress syndrome is not related to quality of life, symptoms of psychiatric disorders or return-to-work: the prospective DACAPO cohort study
}

Sebastian Blecha ${ }^{1 *} \mathbb{D}$, Magdalena Brandl2 , Florian Zeman ${ }^{3}$, Frank Dodoo-Schittko², Susanne Brandstetter ${ }^{2,4}$, Christian Karagiannidis ${ }^{5}$, Thomas Bein ${ }^{1}$, Christian Apfelbacher ${ }^{2,6}$ and for the DACAPO Study Group

\begin{abstract}
Background: Acute respiratory distress syndrome (ARDS) is a life-threatening condition that often requires prolonged mechanical ventilation. Tracheostomy is a common procedure with some risks, on the other hand with potential advantages over orotracheal intubation in critically ill patients. This study investigated the association of tracheostomy with health-related quality of life (HRQoL), symptoms of psychiatric disorders and return-to-work of ARDS survivors.
\end{abstract}

Methods: Data were collected in the context of the prospective observational German-wide DACAPO study. Clinical and demographic patient data and treatment characteristics were obtained from the participating intensive care units (ICU). HRQoL and return-to-work were assessed using patient-reported questionnaires 3, 6 and 12 months after ICU discharge. HRQoL was measured with the Physical and Mental Component Scale of the Short-Form 12 Questionnaire (PCS-12, MCS-12). The prevalence of psychiatric symptoms (depression and post-traumatic stress disorder [PTSD]) was assessed using the Patient Health Questionnaire-9 and the Post-Traumatic Stress Syndrome-14. Physician-diagnosed anxiety and obsessive-compulsive disorder were recorded by patient self-report in the follow-up questionnaires. The associations of tracheostomy with HRQoL, psychiatric symptoms and return-to-work after 12 months were investigated by means of multivariable linear and logistic regression models.

Results: Primary 877 ARDS patients (mean \pm standard deviation: $54 \pm 16$ years, $68 \%$ male) survived and were discharged from ICU. Out of these patients, 478 (54.5\%) were tracheotomised during ICU treatment. After 12 months, patient-reported outcomes could be analysed of 388 (44.2\%) respondents, 205 with tracheostomy and 183 without. One year after ICU discharge, tracheostomy showed no significant association with physical or mental health-related quality of life (PCS-12: $-0.73[-3.96,2.51]$; MCS-12: $-0.71[-4.92,3.49]$ ), symptoms of psychiatric disorders (depression: 0.10 [-1.43, 1.64]; PTSD: 3.31 [-1.81, 8.43]; anxiety: 1.26 [0.41, 3.86]; obsessive-compulsive disorder: 0.59 [0.05, $6.68])$ or return-to-work $(0.71[0.31,1.64])$ in the multivariable analysis (OR [95\%-CI]).

\footnotetext{
${ }^{*}$ Correspondence: Sebastian.Blecha@ukr.de

${ }^{1}$ Department of Anaesthesiology, University Medical Centre Regensburg,

Franz-Josef-Strauss-Allee 11, 93053 Regensburg, Germany

Full list of author information is available at the end of the article
} adaptation, distribution and reproduction in any medium or format, as long as you give appropriate credit to the original author(s) and the source, provide a link to the Creative Commons licence, and indicate if changes were made. The images or other third party material in this article are included in the article's Creative Commons licence, unless indicated otherwise in a credit line to the material. If material is not included in the article's Creative Commons licence and your intended use is not permitted by statutory regulation or exceeds the permitted use, you will need to obtain permission directly from the copyright holder. To view a copy of this licence, visit http://creativecommons.org/licenses/by/4.0/. 
Conclusions: Up to 1 year after ICU discharge, neither HRQoL nor symptoms of psychiatric disorders nor return-towork was affected by tracheostomy.

Trial registration NCT02637011 (ClinicalTrials.gov, Registered 15 December 2015, retrospectively registered)

Keywords: Tracheostomy, ARDS, Intensive care, Health-related quality of life, Return-to-work

\section{Introduction}

Acute respiratory distress syndrome (ARDS), a lifethreatening condition characterised by direct or indirect damage to the lung parenchyma causing critical hypoxemia with or without hypercapnia [1]. Healthcare research in critical care medicine is a relatively new field of interest focusing on the influence of organisational structures, the processes of care on mortality and health-related quality of life (HRQoL) of intensive care unit (ICU) survivors [2-4]. ARDS survivors experience substantial long-term limitations on their physical and mental health and have a high risk of developing psychiatric disorders [5-7].

As part of the complex treatment of ARDS, patients often need prolonged mechanical ventilation. Prolonged endotracheal intubation results in acute laryngeal injuries in more than half of patients and is associated with significantly worse breathing and voicing up to 10 weeks after extubation [8]. Tracheostomy (TT), as the most commonly performed procedure in mechanically ventilated ICU patients, may not only increase patient comfort by reducing airway resistance and dead space but also avoids potential intubation injuries such as oropharyngeal and laryngeal lesions. The advantages of TT over conventional intubation are a shorter duration of sedation and thus promotion of early mobilisation and reduced work of breathing, which might facilitate weaning from mechanical ventilation and hence oral food intake [9]. Nevertheless, the TT is an invasive treatment with potential life-threatening risks. Various complications (e.g. haemorrhage, infection, pneumothorax, tube obstruction, accidental decannulation) have been reported in up to $15 \%$ of ICU patients [10, 11]. A systematic review described that the most common causes of TT-related deaths were haemorrhage, loss of airway and false passage [12]. In the United States, TT results in death or permanent disability in nearly 500 patients each year [11].

To date, outcomes' research in TT has focused on clinical outcomes such as ventilator-free days, duration of sedation, length of stay in the ICU, mortality or survival [13-15]. Patient-reported outcomes such as HRQoL or patient-reported symptoms of psychiatric disease have not been investigated so far, nor has return-to-work. Also, a long-term follow-up perspective is missing.
Therefore, the aim of this study was to analyse the association of TT with HRQoL, the prevalence of psychiatric symptoms and return-to-work of ARDS survivors up to 1 year after ICU discharge. Our hypotheses were that there are possible negative associations between TT and HRQoL, the prevalence of psychiatric symptoms and return-to-work of ARDS survivors.

\section{Methods}

\section{Study design}

The frequency of TT in patients with ARDS was observed in the context of a large prospective German-wide cohort study (DACAPO, acronym of study title: Surviving ARDS: the influence of quality of care and individual patient characteristics on quality of life, ClinicalTrials. gov Identifier: NCT02637011). The study was approved by the Ethics Committee of the University of Regensburg (original approval: December 2013, approval of an amendment: June 2014; file number 13-101-0262) and (if necessary) by the Ethics Committees of the participating study centres. The baseline characteristics and profile of the cohort have been described in more detail elsewhere $[16,17]$. ARDS survivors were asked to complete comprehensive self-report questionnaires 3, 6 and 12 months after their discharge from the ICU.

\section{Patient cohort}

Figure 1 gives an overview of the sample size at the different time points of the study. The study preliminarily included patients with ARDS (according to the Berlin definition [18]) who had been treated at one of 61 ICUs across Germany between September 2014 and April 2016. Written informed consent was obtained from 1.225 patients. Written informed consent was given by the patients or their caregivers or legal guardians during the ICU length of stay.

Out of 877 ICU survivors, 388 (44.2\%) had returned the questionnaire at 12 months. The most frequent reason for dropping out of the study was death after discharge from the ICU $(N=158)$. Other reasons included inability to complete the questionnaire (insufficient knowledge of German or incapability due to morbidity), absence of a person who could provide proxy reports, withdrawal of consent or an invalid address.

The primary endpoint of this study was HRQoL (Short Form-12 self-report questionnaire [SF-12]) of ARDS 


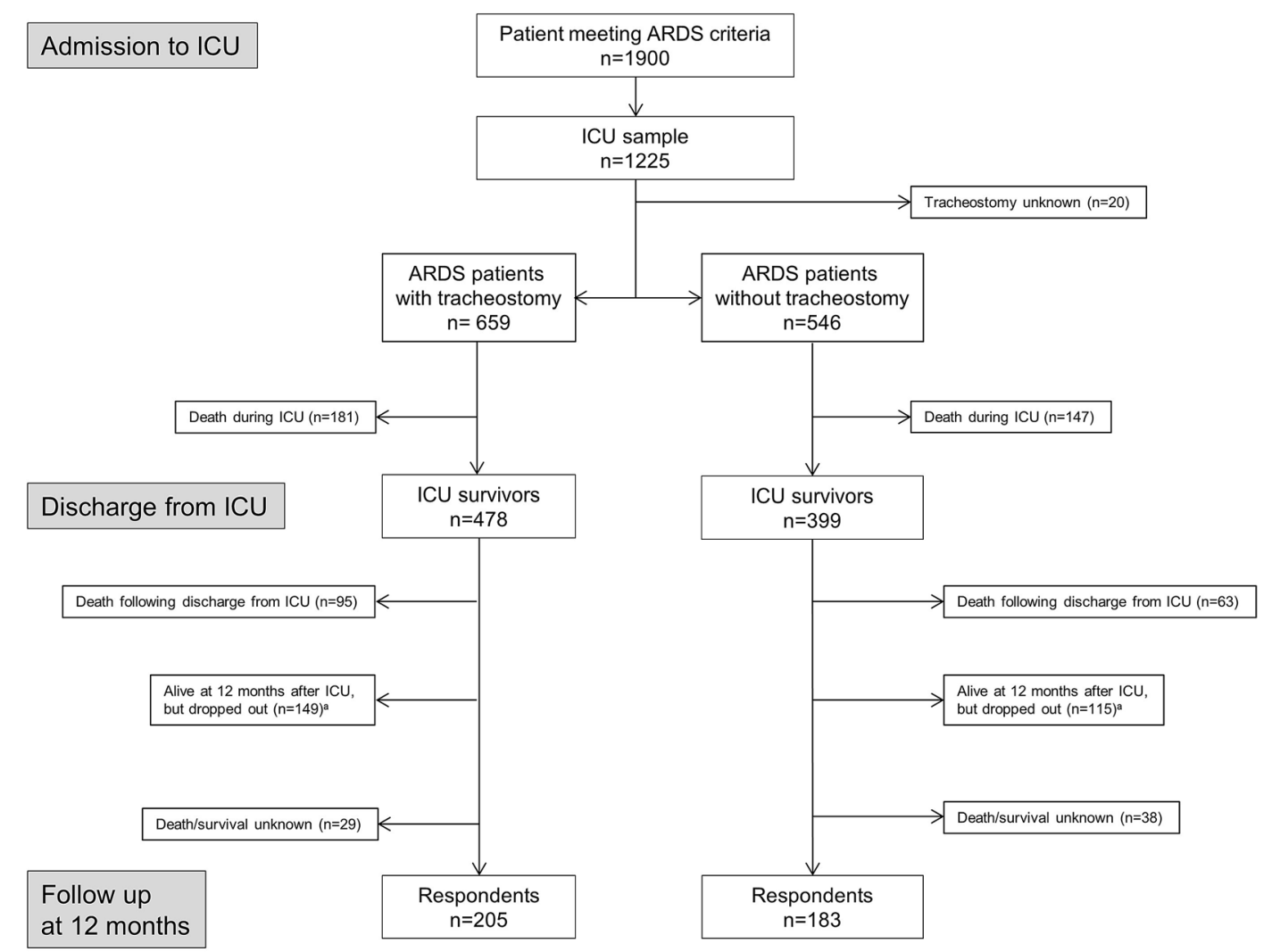

Fig. 1 Consort statement-flow chart of ARDS patients throughout the study (areasons for drop-out for all patients: unable to participate in the study or to understand German, declined participation; incorrect address or new address unknown, organisational failure; survival was assessed by means of local municipal population registries)

survivors up to 1 year after ICU discharge. Secondary endpoints were the prevalence of psychiatric symptoms and return-to-work up to 1 year after ICU discharge.

\section{Data collection and measurement instruments}

Characteristics of patients (age, sex), disease (Sequential Organ Failure Assessment [SOFA] Score, Simplified Acute Physiology Score [SAPS II] and ARDS severity) and treatment (TT, prone position and extracorporeal membrane oxygenation) as well as information on mortality or discharge from the ICU were reported by study physicians or study assistants of the participating ICUs using the electronic data capture system OpenClinica (OpenClinica, LLC; https://www.openclinica.com/). Information on HRQoL and return-to-work was assessed by means of self-report questionnaires at 3, 6 and 12 months after discharge from the ICU. ARDS survivors completed the Short Form-12 self-report questionnaire (SF-12) as a measure of HRQoL and questionnaires on psychopathology. The prevalence of psychiatric symptoms (depression and post-traumatic stress disorder [PTSD]) was assessed using the Patient Health Questionnaire-9 [PHQ-9] and the Post-Traumatic Stress Syndrome-14 [PTSS-14]. Furthermore, patients were asked whether depression, PTSD, anxiety or obsessive compulsive disorder (OCD) had been diagnosed by a physician after ICU discharge. For the screening tools, the cut-off values for being at risk of depression were defined as PHQ-9 $(\geq 5)$ and for PTSD as PTSS-14 $[\geq 45])[19,20]$. The published scoring algorithm of the SF-12 resulted in the Physical Component Summary (PCS-12) and the Mental Component Summary (MCS-12) scores [21]. Scores range from 0 to 100 (higher values indicate better HRQoL), and a score of 50 represents the mean value for the general population (German norm values) [22, 23]. The measuring instruments of HRQoL are described in detail elsewhere [16].

\section{Statistical analyses}

The analyses presented here were pre-specified at the design stage of the study. Data are shown as mean $\pm S D$ for continuous and as absolute and relative frequencies for categorical variables. The Student's $t$ test and the Chi squared test of independence were used for comparing tracheotomised and non-tracheotomised patients. We 
tested whether there was systematic variance between ICUs in relation to the primary outcome at the three follow-ups. These analyses yielded an intraclass correlation coefficient (ICC) close to zero based on the fully unconditional model and non-significant $p$ values for the likelihood ratio tests. For this reason, fixed-effects linear and logistic regression models were applied. The predictive value of TT on HRQOL, psychiatric symptoms and return-to-work after 12 months were assessed by means of multiple linear and multivariable logistic regression models. The following patient- and treatmentrelated confounders were used: patient age, sex, SOFA Score, SAPS II, ARDS severity, body mass index (BMI) and length of ICU stay. The regression coefficient $B$ for the linear regression models and the OR for the logistic regression model were calculated as effect estimates, both accompanied by the corresponding 95\%-confidence intervals (95\%-CI). A $p$ value of $<0.05$ was considered significant. Due to the exploratory nature of this study, no adjustments for multiple comparisons were made. All analyses were performed using the software $\mathrm{R}$ (Version 3.5.1, http://www.r-project.org).

\section{Results}

Out of 1900 patients meeting ARDS criteria, 1205 patients could be analysed (Fig. 1). Of whom 659 (54.7\%) had been tracheotomised during ICU treatment. $68 \%$ of this patient cohort were men; the mean age was 56 years $( \pm 15.8)$. The characteristics of patients with and without TT are shown in Table 1. The body mass index (BMI) was significantly higher in the group of tracheotomised patients $(p=0.010)$. The two groups did not differ with regard to illness severity, which was measured by the SAPS II at ICU admission, the SOFA score and ARDS severity at the time of ARDS diagnosis. For all 1205 patients, the median duration of mechanical ventilation was 16 days (IQR 10-27) and that of ICU length of stay 22 days (IQR 14-36). The median duration of ventilation (20 days [IQR 13-29] vs. 11 days [IQR $6-16], p<0.001$ ) and ICU stay $(p<0.001$, Table 1$)$ was twice as long for tracheotomised patients. Primary 877 ARDS patients survived and discharged from ICU. Out of these patients 478 (54.5\%) were tracheotomised.

The employment status of ARDS patients before and after ICU treatment is shown in Table 2. $328(43.3 \%)$ ARDS survivors had worked full-time or part-time before their critical illness. After 1 year, 186 (54.2\%) of the respondents had returned to work within a median time of 114 days (IQR 72-190) after ICU discharge. Univariate analysis showed that tracheotomised patients were less likely to have returned to work after 12 months than non-tracheotomised patients (35\% vs. $64 \%, p<0.001)$. This association could not be shown in the multivariable analysis $(p=0.416)$ (see Table 4$)$.

According to SF-12 measurement, ARDS survivors had lower HRQoL compared to the score validated from the general population. The differences in PCS-12 and MCS-12 between ARDS survivors with and without TT across the follow-up time points are shown in Fig. 2. In the univariate analysis, patients with TT had significantly worse PCS-12 scores than non-tracheotomised patients across all measured time points after

Table 1 Patient characteristics of the ICU sample $(n=1205)$

\begin{tabular}{|c|c|c|c|c|}
\hline & Tracheostomy $(n=659)$ & $\begin{array}{l}\text { Non-tracheostomy } \\
(n=546)\end{array}$ & $p$ value & Missing $(n)$ \\
\hline Age (years), mean ( \pm SD) & $56.41( \pm 14.87)$ & $56.01( \pm 16.89)$ & 0.663 & 0 \\
\hline \multicolumn{5}{|l|}{ Sex } \\
\hline Men, n (\%) & $454(69 \%)$ & $368(67 \%)$ & 0.580 & 0 \\
\hline Women, $n(\%)$ & $205(31 \%)$ & $178(33 \%)$ & & \\
\hline $\mathrm{BMI}\left(\mathrm{kg} / \mathrm{m}^{2}\right)$, mean $( \pm \mathrm{SD})$ & $29.62( \pm 9.34)$ & $28.29( \pm 6.94)$ & $0.010^{*}$ & 154 \\
\hline \multicolumn{5}{|l|}{ Severity of ARDS ${ }^{a}$} \\
\hline Mild, $n(\%)$ & $46(9 \%)$ & $44(10 \%)$ & 0.711 & 273 \\
\hline Moderate, $n(\%)$ & $224(44 \%)$ & $182(42 \%)$ & & \\
\hline Severe, $n(\%)$ & $238(47 \%)$ & $211(48 \%)$ & & \\
\hline $\mathrm{SAPS}^{\mathrm{b}}$, mean $( \pm \mathrm{SD})$ & $65( \pm 41.36)$ & $51( \pm 41.02)$ & 0.655 & 124 \\
\hline SOFA score ${ }^{a}$, mean $( \pm S D)$ & $8.46( \pm 3.58)$ & $8.10( \pm 3.34)$ & 0.098 & 148 \\
\hline Duration of ICU stay, days, median (IQR) & $30(20-44)$ & $15(10-23)$ & $<0.001^{*}$ & 44 \\
\hline
\end{tabular}

ARDS acute respiratory distress syndrome, BMI body mass index, ICU intensive care unit, SAPS Simplified Acute Physiology Score, SOFA sequential organ failure assessment

${ }^{*} p<0.05$

a Measured at the time of ARDS diagnosis

${ }^{b}$ Measured at ICU admission 
Table 2 Univariate analysis of the employment status of ARDS patients before ICU treatment and return-to-work

\begin{tabular}{|c|c|c|c|c|}
\hline & Tracheostomy & Non-tracheostomy & $p$ value & Missing (n) \\
\hline \multicolumn{5}{|l|}{ ICU sample $(n=1205)$} \\
\hline Previous employment, $n$ (\%) & $211(36.1)$ & $197(40.6)$ & 0.133 & 136 \\
\hline No previous employment, $n(\%)$ & $373(63.9)$ & $288(59.4)$ & & \\
\hline \multicolumn{5}{|l|}{ ICU survivors $(n=877)$} \\
\hline Previous employment, $n$ (\%) & $162(39)$ & $166(48.4)$ & $0.01^{*}$ & 119 \\
\hline No previous employment, $n(\%)$ & $253(61)$ & $177(51.6)$ & & \\
\hline \multicolumn{5}{|c|}{ Respondents after 12 months $(n=388)$} \\
\hline Return-to-work, $n(\%)$ & $34(35)$ & $66(64)$ & $p<0.001^{*}$ & 189 \\
\hline
\end{tabular}

Return-to-work could only analysed in patients which worked before the critical illness ICU intensive care unit

${ }^{*} p<0.05$
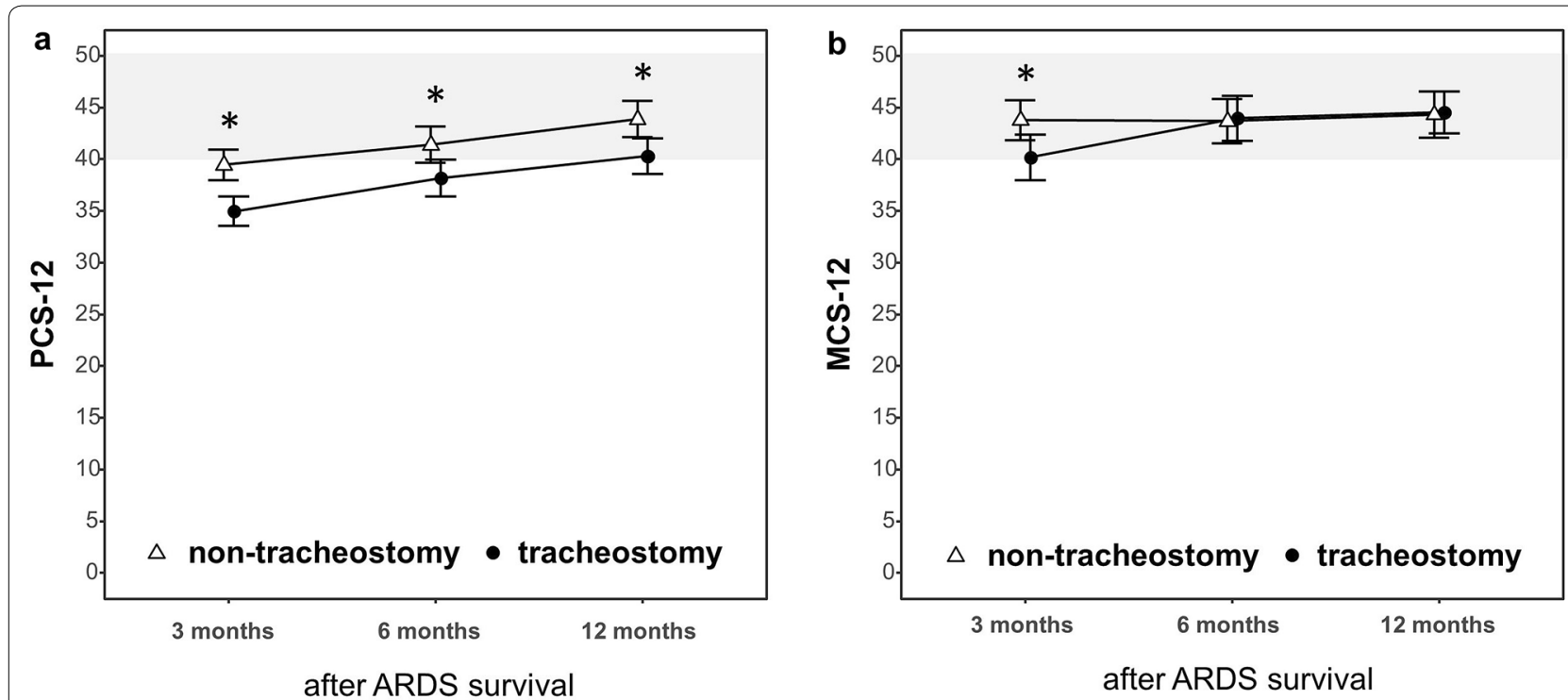

Fig. 2 Univariate analysis of Short Form-12 (SF-12) self-report response of ARDS survivors across follow-up time points $\left({ }^{*} p<0.05\right.$; means and 95\%-CI). a Physical Component Summary of SF-12 [PCS-12]. b Mental Component Summary of SF-12 [MCS-12]); the mean score of the general population is 50; one standard deviation is marked in grey

ICU discharge (Fig. 2; Table 3), but no significance was found in the multivariable analysis (Table 4). In the univariate analysis, MCS-12 scores were significantly impaired for tracheotomised patients 3 months after ICU discharge $(p=0.016)$ but did not differ between the two groups after 6 and 12 months (Fig. 2). The multivariable analysis of MCS-12 did not show any differences 1 year after ICU discharge $(p=0.834)$ (Table 4$)$. In the univariate and multivariate analyses, psychiatric symptoms (PHQ-9, PTSS-14) and reported psychiatric disorders (depression, PTSD, anxiety and OCD) had not been affected by TT in patients up to 1 year after ARDS (Tables 3 and 4).

\section{Discussion}

This study analysed the influence of TT on HRQoL, prevalence of psychiatric symptoms and return-to-work in 388 ARDS survivors 1 year after ICU discharge. The main finding was that TT was not significantly associated with physical (PCS-12) or mental impairment in quality of life (MCS-12). Secondary findings were (1) TT was not significantly related to the prevalence of psychiatric disorders and (2) TT was not significantly associated with return-to-work of ARDS survivors after 12 months.

Thus, the hypotheses underlying this study could not be confirmed. However, we did observe that TT was associated with a significant increase of ICU length of stay. ICU length of stay is a known independent factor 
Table 3 Univariate analysis of HRQoL and symptoms of psychiatric disorders in ARDS survivors after 12 months $(n=388)$

\begin{tabular}{|c|c|c|c|c|}
\hline & Tracheostomy $(n=205)$ & $\begin{array}{l}\text { Non-tracheostomy } \\
(n=183)\end{array}$ & $p$ value & Missing (n) \\
\hline PCS-12 ${ }^{\mathrm{a}}$, mean $( \pm S D)$ & $40.3( \pm 10.8)$ & $43.9( \pm 11.0)$ & $0.005^{*}$ & 83 \\
\hline MCS-12a mean $( \pm S D)$ & $44.5( \pm 12.8)$ & $44.3( \pm 14.0)$ & 0.887 & 83 \\
\hline PHQ-9a ${ }^{\mathrm{a}}$, mean $( \pm S D)$ & $6.5( \pm 5.1)$ & $6.1( \pm 5.4)$ & 0.517 & 24 \\
\hline PTSS-14 ${ }^{\mathrm{a}}$, mean $( \pm S D)$ & $35.3( \pm 18.0)$ & $32.6( \pm 17.6)$ & 0.156 & 25 \\
\hline \multicolumn{5}{|l|}{ Depression $^{b}$} \\
\hline Yes, $n(\%)$ & $32(16 \%)$ & $18(10 \%)$ & 0.078 & 18 \\
\hline \multicolumn{5}{|l|}{ Anxiety disorder ${ }^{b}$} \\
\hline Yes, $n(\%)$ & $20(10 \%)$ & $11(6 \%)$ & 0.170 & 34 \\
\hline \multicolumn{5}{|l|}{ PTSD $^{b}$} \\
\hline Yes, $n(\%)$ & $20(10 \%)$ & $16(9 \%)$ & 0.721 & 22 \\
\hline \multicolumn{5}{|l|}{ OCD $^{b}$} \\
\hline Yes, n (\%) & $6(3 \%)$ & $5(3 \%)$ & 0.883 & 27 \\
\hline
\end{tabular}

MCS-12 Mental Component Scale of Short-Form 12 Questionnaire, PCS-12 Physical Component Scale of Short-Form 12 Questionnaire, OCD obsessive-compulsive disorder, PTSD post-traumatic stress disorder, PHQ-9 Patient Health Questionnaire-9, PTSS-14 Post-Traumatic Stress Syndrome 14-Questions Inventory

${ }^{*} p<0.05$

${ }^{a}$ Health-related quality of life and symptoms of psychiatric disorders (depression, PTSD) were diagnosed according to the results of patient self-reported questionnaires

b Psychiatric disorders diagnosed by a physician were recorded by patient self-report in the follow-up questionnaires

Table 4 Multivariable linear and logistic regression models on HRQoL, psychiatric symptoms and return-to-work after 12 months (adjusted for age, sex, BMI, severity of ARDS, SOFA score, SAPS-II and length of ICU stay)

\begin{tabular}{|c|c|c|c|}
\hline Dependent variable & Independent variable & B $(95 \%-C l)$ & $\mathbf{p}$ \\
\hline PCS-12a $(n=305)$ & Tracheostomy & $-0.73(-3.96,2.51)$ & 0.659 \\
\hline $\operatorname{MCS}-12^{\mathrm{a}}(n=305)$ & Tracheostomy & $-0.71(-4.92,3.49)$ & 0.739 \\
\hline PHQ-9a $(n=364)$ & Tracheostomy & $0.10(-1.43,1.64)$ & 0.894 \\
\hline \multirow[t]{2}{*}{ PTSS-14a $(n=363)$} & Tracheostomy & $3.31(-1.81,8.43)$ & 0.204 \\
\hline & & OR $(95 \%-\mathrm{Cl})$ & \\
\hline Depression $^{\mathrm{b}}(n=370)$ & Tracheostomy & $1.52(0.61,3.78)$ & 0.368 \\
\hline Anxiety disorder ${ }^{\mathrm{b}}(n=354)$ & Tracheostomy & $1.26(0.41,3.86)$ & 0.691 \\
\hline $\operatorname{PTSD}^{\mathrm{b}}(n=366)$ & Tracheostomy & $0.91(0.29,2.82)$ & 0.870 \\
\hline $\operatorname{OCD}^{\mathrm{b}}(n=361)$ & Tracheostomy & $0.59(0.05,6.68)$ & 0.667 \\
\hline Return-to-work ${ }^{\mathrm{b}}(n=199)$ & Tracheostomy & $0.71(0.31,1.64)$ & 0.416 \\
\hline
\end{tabular}

$B$ regression coefficient, $95 \%$-Cl 95\% confidence interval, MCS-12 Mental Component Scale of Short-Form 12 Questionnaire, OCD obsessive-compulsive disorder, OR odds ratio, PCS-12 Physical Component Scale of Short-Form 12 Questionnaire, PTSD post-traumatic stress disorder, $P H Q-9$ Patient Health Questionnaire-9, PTSS-14 Post-Traumatic Stress Syndrome 14-Questions Inventory

${ }^{*} p<0.05$

a Health-related quality of life and symptoms of psychiatric disorders (depression, PTSD) were diagnosed according to the results of patient self-reported questionnaires

b Psychiatric disorders diagnosed by a physician were recorded by patient self-report in the follow-up questionnaires

associated with increased stationary healthcare use and 1-year mortality after ICU discharge and should be considered when deciding for the best time point of TT in critical ill patients $[24,25]$. In our study, associations observed in univariate analyses were lost mainly due to the strong confounding effect of ICU length of stay.
A current systematic review of patient-important outcomes for critically ill patients in randomised controlled clinical studies has shown ICU mortality to be the most frequently measured clinical outcome. Only $10 \%$ of studies have included at least one patient-important outcome in addition to mortality after ICU discharge [26]. 
It should be noted that, in contrast to mortality, HRQoL is a complex construct that contains individual aspects with multiple dimensions, often operationalised as social, somatic and psychological variables [4]. The individual dimensions of HRQoL could be recorded by different measurement tools and must be correlated for a better comparison of patient-reported outcomes [27]. In an Italian study, 137 tracheotomised patients with respiratory and neurological diseases were analysed in relation to ICU mortality and HRQoL. Patients tracheotomised because of respiratory disease had a high ICU mortality rate of $50 \%$; only 25 patients (20.5\%) were still alive after 1 year. HRQoL of all tracheotomised patients was moderately compromised after 1 year, but the group of patients with respiratory diseases showed better HRQoL during follow-up [28]. In the present study, HRQoL was not impaired by TT.

Symptoms of psychiatric disorders were often reported after survival of ARDS [6,29]. As an example, up to $27 \%$ of critical illness survivors suffered from PTSD, and depression was reported in $40 \%$ of ARDS survivors [30, 31]. In the present study, TT did not influence the occurrence of psychiatric disorders. According to the results of the self-reported questionnaires shown in Tables 3 and 4, 25.9\% of ARDS survivors had symptoms of PTSD (cut-off scores for symptoms of PTSD: $\geq 45$ ) and 55.6\% symptoms of depression (PHQ-9 score $\geq 5$ ) at the 1-year follow-up $[19,20]$.

Furthermore, TT did not affect return-to-work in ARDS survivors in this study. More than $50 \%$ of 1-year survivors had returned to work after a median of 16 weeks after ICU discharge. Considering the different socioeconomic systems, an US survey including 379 previously employed ARDS survivors found that 213 (56\%) patients had returned to work after a median of 13 weeks after hospital discharge [32]. Nevertheless, the fact remains that nearly $50 \%$ of patients were unemployed, which may have resulted in family problems and loss of substantial earnings. A 5-year follow-up of ARDS survivors showed that nearly one-third of previously employed ARDS survivors had never returned to work [33].

$\mathrm{TT}$ is one of the most common surgical procedures in patients with acute respiratory failure. TT practices vary substantially amongst disciplines, ICUs and institutions [34]. The TT rate of 55\% found in this Germany-wide study seems to be rather high and could be explained by the inclusion of a higher number of patients with severe ARDS. In the worldwide LUNG-SAFE study, only 13\% of patients with ARDS had received TT during their length of ICU stay; yet, the rate in European countries was higher at $15.7 \%$ [15]. The ICU length of stay was also significantly longer for patients with TT (11 vs. 8 days). One possible explanation might be that the transfer of tracheostomised patients to a normal ward is difficult because of the elaborate airway management and more intensive care. Freeman and colleagues analysed over 44,000 patients with acute respiratory failure $(10.8 \%$ of patients with TT) and found longer ICU treatment (24 vs. 7 days) in tracheotomised patients [35]. In our study, the BMI was significantly higher in the tracheotomised group. A recent study from the US which also investigated patient factors associated with 30-day survival after TT did not find any influence of BMI and socioeconomic factors [13].

\section{Strengths and limitations}

The strengths of the present study are its prospective design with three time point of follow-ups, the large number of included patients with ARDS from hospitals across Germany and the detailed collection of data on HRQoL and individual patient characteristics. Despite our best efforts to follow up each patient, the number of drop-outs was rather high, which may have resulted in attrition bias limiting this study. The instruments used for screening mental disorders do not allow making diagnoses such as major depression disorders and PTSD; only symptoms or the risk of being affected by such a disorder could be recorded. To the best of our knowledge, this is the largest multicentre study investigating the association of TT with return-to-work and patient-reported HRQoL as well as symptoms of psychiatric disorders and returnto-work in ARDS survivors.

\section{Conclusion}

In summary, TT resulted in prolonged intensive care treatment of ARDS survivors but did not seem to have an association with physical or mental HRQoL, symptoms of psychiatric disorders or return-to-work 1 year after ICU discharge.

\section{Abbreviations}

ARDS: Acute respiratory distress syndrome; BMI: Body mass index; $\mathrm{HRQOL}$ : Health-related quality of life; ICU: Intensive care unit; MCS-12: Mental Component Summary; OCD: Obsessive compulsive disorders; PCS-12: Physical Component Summary; PHQ-9: Patient Health Questionnaire-9; PTSD: Posttraumatic stress disorders; PTSS-14: Post-Traumatic Stress Syndrome 14-Questions Inventory; SAPS II: Simplified Acute Physiology Score; SF-12: Short Form-12 self-report questionnaire; SOFA: Sequential organ failure assessment; TT: Tracheostomy.

\section{Acknowledgements}

We are grateful to Monika Schoell for the linguistic revision of the manuscript. We are indebted to all the intensivists and study assistants across Germany who had recruited patients for the DACAPO study with great commitment: Aachen, Aachen University Hospital RWTH Aachen, Department of Anesthesiology (PD Dr. Johannes Bickenbach, Dr. Thorben Beeker, PD Dr. Tobias Schürholz, Jessica Pezechk); Amberg, Klinikum Amberg, Department for Anaesthesiology (Dr. Jens Schloer); Augsburg, Klinikum Augsburg (Dr. Ulrich Jaschinski, Ilse Kummer); Bamberg, Sozialstiftung Bamberg Hospital, Department for Anaesthesiology (Dr. Oliver Kuckein); Berlin, Charité 
- University Medicine Berlin, Department of Anaesthesiology and Intensive Care Medicine (PD Dr. Steffen Weber-Carstens, Dr. Anton Goldmann, Dr. Stefan Angermair, Krista Stoycheva); Berlin, HELIOS Klinikum Berlin-Buch, Department of Intensive Care Medicine (Prof. Dr. Jörg Brederlau, Nadja Rieckehr, Gabriele Schreiber, Henriette Haennicke); Bielefeld, Ev. Krankenhaus Bielefeld. Department of Anesthesiology, Intensive Care Medicine, Emergency Medicine and Pain Therapy (Dr. Friedhelm Bach, Dr. Immo Gummelt, Dr. Silke Haas, Catharina Middeke, Dr. Ina Vedder, Marion Klaproth); Bochum, Ruhr University Bochum, Department of Anaesthesiology (Prof. Dr. Michael Adamzik, Dr. Jan Karlik, Dr. Stefan Martini, Luisa Robitzky); Bonn, University Hospital Bonn, Department of Anesthesiology and Intensive Care Medicine (Prof. Dr. Christian Putensen, Dr. Thomas Muders, Ute Lohmer); Bremen, Klinikum Bremen-Mitte, Department of Anesthesiology (Prof. Dr. Rolf Dembinski); Deggendorf, Medical Center, Department of Anaesthesiology and Intensive Care Medicine (Dr. Petra Schäffner, Dr. Petra Wulff-Werner); Dortmund, Klinikum Dortmund, Department of Critical Care Medicine (Elke Landsiedel-Mechenbier, Daniela Nickoleit-Bitzenberger, Ann-Kathrin Silber); Dresden, University Hospital Dresden Carl Gustav Carus, Department of Anesthesiology and Intensive Care Medicine (Prof. Dr. Maximilian Ragaller, Prof. Dr. Marcello Gama de Abreu, Alin Ulbricht, Linda Reisbach); Frankfurt am Main, University Hospital Frankfurt, Department of Anaesthesiology, Intensive Care Medicine and Pain Therapy (Prof. Dr. Kai Zacharowski, Prof. Dr. Patrick Meybohm, Simone Lindau, Haitham Mutlak); Freiburg, University Medical Center Freiburg, Department of Anaesthesiology and Critical Care Medicine Freiburg (Prof. Dr. Alexander Hötzel, Dr. Johannes Kalbhenn); Freising, Klinikum Freising, Department of Anaesthesiology (Dr. Christoph Metz, Dr. Stefan Haschka); Göppingen, Klinik am Eichert, ALB FILS Kliniken, Department of Anaesthesiology and Intensive Care (Dr. Stefan Rauch); Göttingen, University Medical Center, Department of Anaesthesiology, Emergency and Intensive Care Medicine (Prof. Dr. Michael Quintel, Dr. Lars-Olav Harnisch, Dr. Sophie Baumann, Andrea Kernchen); Greifswald, University Medicine Greifswald, Department of Internal Medicine B (Dr. Sigrun Friesecke, Sebastian Maletzki); Hamburg, University Hospital Hamburg-Eppendorf, Department of Intensive Care Medicine, Center of Anesthesiology and Intensive Care Medicine (Prof. Dr. Stefan Kluge, Dr. Olaf Boenisch, Dr. Daniel Frings, Birgit Füllekrug, Dr. Nils Jahn, Dr. Knut Kampe, Grit Ringeis, Brigitte Singer, Dr. Robin Wüstenberg); Hannover, Hannover Medical School, Department of Anaesthesiology and Intensive Care Medicine (Dr. Jörg Ahrens, Dr. Heiner Ruschulte, Dr. Andre Gerdes, Dr. Matthias Groß); Hannover, Hannover Medical School, Department of Respiratory Medicine (Dr. Olaf Wiesner, Aleksandra Bayat-Graw); Heidelberg, University of Heidelberg, Department of Anaesthesiology (Dr. Thorsten Brenner, Dr. Felix Schmitt, Anna Lipinski); Herford, Klinikum Herford, Clinic for Anaesthesiology, Surgical Intensive Care Medicine, Emergency Care Medicine, Pain Management (Prof. Dr. Dietrich Henzler, Dr. Klaas Eickmeyer, Dr. Juliane Krebs, Iris Rodenberg); Homburg, Homburg University Medical Centre, Department of Anaesthesiology, Intensive Care and Pain Medicine (Dr. Heinrich Groesdonk, Kathrin Meiers, Karen Salm, Prof. Dr. Thomas Volk); Ibbenbüren, Ibbenbüren General Hospital, Division of Thoracic Surgery and Lung Support (Prof. Dr. Stefan Fischer, Basam Redwan); Immenstadt, Kempten-Oberallgaeu Hospitals, Clinic for Pneumology, Thoracic Oncology, Sleep- and Respiratory Critical Care (Dr. Martin Schmölz, Dr. Kathrin Schumann-Stoiber, Simone Eberl); Ingolstadt, Klinikum Ingolstadt, Department of Anaesthesiology and Critical Care Medicine (Prof. Dr. Gunther Lenz, Thomas von Wernitz-Keibel, Monika Zackel); Jena, Jena University Hospital, Deptartment of Anesthesiology and Intensive Care Therapy (Dr. Frank Bloos, Dr. Petra Bloos, Anke Braune, Anja Haucke, Almut Noack, Steffi Kolanos, Heike Kuhnsch, Karina Knuhr-Kohlberg); Kassel, Klinikum Kassel, Department of Anaesthesiology (PD Dr. Markus Gehling); Kempten, Klinikum Kempten-Oberallgäu gGmbH, Department for Anesthesia and Operative Intensive Care (Prof. Dr. Mathias Haller, Dr. Anne Sturm, Dr. Jannik Rossenbach); Kiel, University Medical Center Schleswig-Holstein, Campus Kiel, Department of Anesthesiology and Intensive Care Medicine (Dr. Dirk Schädler, Stefanie D'Aria); Köln, Cologne-Merheim Hospital, Department of Pneumology and Critical Care Medicine (Prof. Dr. Christian Karagiannidis, Dr. Stephan Straßmann, Prof. Dr. Wolfram Windisch); Köln, University Hospital of Cologne, Department of Anaesthesiology and Intensive Care Medicine (Prof. Dr. Thorsten Annecke, PD Dr. Holger Herff); Langen, Asklepios Kliniken Langen-Seligenstadt, Department of Anesthesiology and Intensive Care Medicine (Dr. Michael Schütz); Leipzig, University of Leipzig, Department of Anesthesiology and Intensive Care Medicine (PD Dr. Sven Bercker, Hannah Reising, Mandy Dathe, Christian Schlegel); Ludwigsburg, Klinikum Ludwigsburg, Academic Teaching Hospital, University of Heidelberg, Department of
Anaesthesiology (Katrin Lichy); Ludwigshafen, Klinikum Ludwigshafen, Department of Anesthesiology and Intensive Care Medicine (Prof. Dr. Wolfgang Zink, Dr. Jana Kötteritzsch); Mainz, University Medical Center Mainz, Department of Anaesthesiology (Dr. Marc Bodenstein, Susanne Mauff, Peter Straub); Magdeburg, Magdeburg University Medical Centre, Department of Anaesthesiology and Intensive Care Medicine (Dr. Christof Strang, Florian Prätsch, Prof. Dr. Thomas Hachenberg); Mannheim, University Medical Center Mannheim, Department of Anaesthesiology and Surgical Intensive Care Medicine (Dr. Thomas Kirschning, Dr. Thomas Friedrich, Dr. Dennis Mangold); Marburg, University Hospital, Department of Anaesthesiology (Dr. Christian Arndt, Tilo Koch); Mönchengladbach, Kliniken Maria-Hilf GmbH, Department of Cardiology (Dr. Hendrik Haake, Katrin Offermanns); München, Bogenhausen Hospital, Department of Anaesthesiology (Prof. Dr. Patrick Friederich, Dr. Florian Bingold); München, Klinikum Großhadern, Department of Anaesthesiology (Dr. Michael Irlbeck, Prof. Dr. Bernhard Zwissler); München, Klinikum Neuperlach, Städtisches Klinikum München GmbH, Department of Anesthesiology, Critical Care and Pain Medicine (PD Dr. Ines Kaufmann); München, Klinikum rechts der Isar, Department for Anaesthesiology of the Technical University of Munich (Dr. Ralph Bogdanski, Dr. Barbara Kapfer, Dr. Markus Heim, PD Dr. Günther Edenharter); Münster, University Hospital Münster, Department for Anaesthesiology, Intensive Care Medicine and Pain Therapy, (Prof. Dr. Björn Ellger, Daniela Bause); Neumarkt, Kliniken des Landkreises Neumarkt i.d.OPf, Department for Anaesthesiology and Intensive Care Medicine (Dr. Götz Gerresheim); Nürnberg, General Hospital Nuremberg, Paracelsus Medical University, Department of Emergency Medicine and Intensive Care (Dr. Dorothea Muschner, Prof. Dr. Michael Christ, Arnim Geise); Osnabrück, Marienhospital Osnabrück, Department of Anaesthesiology (PD Dr. Martin Beiderlinden, Dr. Thorsten Heuter); Passau, Klinikum Passau, Department for Anaesthesiology (Dr. Alexander Wipfel); Regensburg, Caritas Krankenhaus St. Josef, Department for Anaesthesiology (Dr. Werner Kargl, Dr. Marion Harth, Dr. Christian Englmeier); Regensburg, Regensburg University Hospital, Department of Anaesthesiology, Operative Intensive Care (Prof. Dr. Thomas Bein, Dr. Sebastian Blecha, Dr. Kathrin Thomann-Hackner, Marius Zeder); Stuttgart, Katharinenhospital, Department of Anesthesiology (Dr. Markus Stephan); Traunstein, Klinikum Traunstein, Department of Anaesthesiology (Dr. Martin Glaser); Tübingen, Tübingen University Hospital, EberhardKarls University Tübingen, Department of Anaesthesiology and Intensive Care Medicine (PD Dr. Helene Häberle); Ulm, Ulm University, Department of Anesthesiology (Prof. Dr. Hendrik Bracht, Christian Heer, Theresa Mast); Würzburg, University of Würzburg, Department of Anaesthesia and Critical Care (PD Dr. Markus Kredel, PD Dr. Ralf Müllenbach)

Further, we are grateful to previous members of the Regensburg DACAPO study team (medical documentation: Phillip Sebök, study physician: Kathrin Thomann-Hackner), to the members of the Advisory Board of the DACAPOStudy (Prof. Dr. Julika Loss, Prof. Dr. Bernhard Graf, Prof. Dr. Michael Leitzmann, Prof. Dr. Michael Pfeifer, Regensburg, Germany) and to our student assistants (Simon Bein, Vreni Brunnthaler, Carina Forster, Stefanie Hertling, Sophie Höhne, Carolin Schimmele, Elisa Valletta).

\section{Authors' contributions}

SB and TB had the idea for the study. SB, MB, FZ, FDS, SuB, TB and CA contributed to conception and design of the study. SB, FDS, SuB, MB, CK, TB and CA helped providing study materials or patient reports. FZ, MB, CK and SB conducted the data analysis. FZ, MB, CK, SuB, FDS, TB and CA helped interpreting the data. SB drafted the manuscript. All authors reviewed the manuscript for important intellectual content. All authors read and approved the final manuscript.

\section{Funding}

The German Ministry of Education and Research (Bundesministerium für Bildung und Forschung, Funding Number 01GY1340) funds the study.

\section{Availability of data and materials}

Data are available depending permission from the original data holders (the two principal investigators (PIs) Christian Apfelbacher and Thomas Bein). Due to data economy and subsequently data protection, only the variables required for the analysis project will be provided.

\section{Ethics approval and consent to participate}

The study has been approved by the Ethics Committee of the University of Regensburg (file number 13-101-0262) and where necessary by Ethics 
Committees of the participating study centres. Written informed consent was obtained from caregivers/legal guardians and additionally from those patients who survived ICU.

\section{Consent for publication}

Not applicable.

\section{Competing interests}

CK received travel grants and lecture fees from Maquet, Rastatt, Germany. TB is a member of the German ARDS-Network and received honoraria for lectures and activities as member of the advisory board of Novalung, Heilbronn, Germany. All other authors (SB, MB, FZ, FDS, SuB and CA) declare no conflict of interest.

\section{Author details}

1 Department of Anaesthesiology, University Medical Centre Regensburg, Franz-Josef-Strauss-Allee 11, 93053 Regensburg, Germany. ${ }^{2}$ Medical Sociology, Institute of Epidemiology and Preventive Medicine, University of Regensburg, Regensburg, Germany. ${ }^{3}$ Centre of Clinical Studies, University Medical Centre Regensburg, Regensburg, Germany. ${ }^{4}$ University Children's Hospital Regensburg (KUNO), University of Regensburg, Regensburg, Germany. ${ }^{5}$ Department of Pneumology and Critical Care Medicine, Cologne-Merheim Hospital, ARDS and ECMO Centre, Kliniken der Stadt Köln gGmbH, Witten/Herdecke University Hospital, Cologne, Germany. ${ }^{6}$ Institute of Social Medicine and Health Economics, Otto von Guericke University Magdeburg, Magdeburg, Germany.

Received: 21 January 2020 Accepted: 28 April 2020 Published online: 06 May 2020

\section{References}

1. Matthay MA, Ware LB, Zimmerman GA. The acute respiratory distress syndrome. J Clin Invest. 2012;122:2731-40. https://doi.org/10.1172/JCI60 331.

2. Sakr Y, Moreira CL, Rhodes A, Ferguson ND, Kleinpell R, Pickkers P, et al. The impact of hospital and ICU organizational factors on outcome in critically ill patients: results from the extended prevalence of infection in intensive care study. Crit Care Med. 2015;43:519-26. https://doi. org/10.1097/CCM.0000000000000754.

3. Turnbull AE, Rabiee A, Davis WE, Nasser MF, Venna VR, Lolitha R, et al. Outcome measurement in ICU survivorship research from 1970 to 2013: a scoping review of 425 publications. Crit Care Med. 2016;44:1267-77. https://doi.org/10.1097/CCM.0000000000001651.

4. Dinglas VD, Faraone LN, Needham DM. Understanding patient-important outcomes after critical illness: a synthesis of recent qualitative, empirical, and consensus-related studies. Curr Opin Crit Care. 2018;24:401-9. https ://doi.org/10.1097/MCC.0000000000000533.

5. Herridge MS, Tansey CM, Matté A, Tomlinson G, Diaz-Granados N, Cooper $A$, et al. Functional disability 5 years after acute respiratory distress syndrome. N Engl J Med. 2011;364:1293-304. https://doi.org/10.1056/NEJMo a1011802.

6. Bienvenu OJ, Friedman LA, Colantuoni E, Dinglas VD, Sepulveda KA, Mendez-Tellez $\mathrm{P}$, et al. Psychiatric symptoms after acute respiratory distress syndrome: a 5-year longitudinal study. Intensive Care Med. 2018;44:38-47. https://doi.org/10.1007/s00134-017-5009-4.

7. Fan E, Dowdy DW, Colantuoni E, Mendez-Tellez PA, Sevransky JE, Shanholtz C, et al. Physical complications in acute lung injury survivors: a two-year longitudinal prospective study. Crit Care Med. 2014;42:849-59. https://doi.org/10.1097/CCM.0000000000000040.

8. Shinn JR, Kimura KS, Campbell BR, Sun Lowery A, Wootten CT, Garrett CG, et al. Incidence and outcomes of acute laryngeal injury after prolonged mechanical ventilation. Crit Care Med. 2019. https://doi.org/10.1097/ CCM.0000000000004015.

9. Putensen C, Theuerkauf N, Guenther U, Vargas M, Pelosi P. Percutaneous and surgical tracheostomy in critically ill adult patients: a meta-analysis. Crit Care. 2014;18:544. https://doi.org/10.1186/s13054-014-0544-7.

10. Epstein SK. Late complications of tracheostomy. Respir Care. 2005:50:542-9.
11. Das P, Zhu H, Shah RK, Roberson DW, Berry J, Skinner ML. Tracheotomyrelated catastrophic events: results of a national survey. Laryngoscope. 2012;122:30-7. https://doi.org/10.1002/lary.22453.

12. Klemm E, Nowak AK. Tracheotomy-related deaths. Dtsch Arztebl Int. 2017;114:273-9. https://doi.org/10.3238/arztebl.2017.0273.

13. Kashlan KN, Williams AM, Chang SS, Yaremchuk KL, Mayerhoff R. Analysis of patient factors associated with 30-day mortality after tracheostomy. Laryngoscope. 2018. https://doi.org/10.1002/lary.27345.

14. Scales DC, Thiruchelvam D, Kiss A, Redelmeier DA. The effect of tracheostomy timing during critical illness on long-term survival. Crit Care Med. 2008;36:2547-57. https://doi.org/10.1097/CCM.0b013e31818444a5.

15. Abe T, Madotto F, Pham T, Nagata I, Uchida M, Tamiya N, et al. Epidemiology and patterns of tracheostomy practice in patients with acute respiratory distress syndrome in ICUs across 50 countries. Crit Care. 2018;22:195. https://doi.org/10.1186/s13054-018-2126-6.

16. Dodoo-Schittko F, Brandstetter S, Brandl M, Blecha S, Quintel M, WeberCarstens $\mathrm{S}$, et al. German-wide prospective DACAPO cohort of survivors of the acute respiratory distress syndrome (ARDS): a cohort profile. BMJ Open. 2018;8:e019342. https://doi.org/10.1136/bmjopen-2017-019342.

17. Dodoo-Schittko F, Brandstetter S, Brandl M, Blecha S, Quintel M, WeberCarstens S, et al. Characteristics and provision of care of patients with the acute respiratory distress syndrome: descriptive findings from the DACAPO cohort baseline and comparison with international findings. J Thorac Dis. 2017;9:818-30. https://doi.org/10.21037/jtd.2017.03.120.

18. Ranieri VM, Rubenfeld GD, Thompson BT, Ferguson ND, Caldwell E, Fan $E$, et al. Acute respiratory distress syndrome: the Berlin definition. JAMA. 2012;307:2526-33. https://doi.org/10.1001/jama.2012.5669.

19. Parker AM, Sricharoenchai T, Raparla S, Schneck KW, Bienvenu OJ, Needham DM. Posttraumatic stress disorder in critical illness survivors: a metaanalysis. Crit Care Med. 2015;43:1121-9. https://doi.org/10.1097/ CCM.0000000000000882.

20. Kroenke K, Spitzer RL, Williams JBW. The PHQ-9. J Gen Intern Med. 2001;16:606-13. https://doi.org/10.1046/j.1525-1497.2001.016009606.x.

21. Gandek B, Ware JE, Aaronson NK, Apolone G, Bjorner JB, Brazier JE, et al. Cross-validation of item selection and scoring for the SF-12 Health Survey in nine countries: results from the IQOLA Project. International Quality of Life Assessment. J Clin Epidemiol. 1998;51:1171-8.

22. Bullinger M. German translation and psychometric testing of the SF-36 Health Survey: Preliminary results from the IQOLA Project. International Quality of Life Assessment. Soc Sci Med. 1995;41:1359-66.

23. Stieglitz R-D. Bullinger, M. \& Kirchberger, I. (1998). SF-36. Fragebogen zum Gesundheitszustand. Göttingen: Hogrefe. Preis DM 298. Zeitschrift für Klinische Psychologie und Psychotherapie. 1999;28:143-5. https://doi. org/10.1026//0084-5345.28.2.143.

24. Brandstetter S, Dodoo-Schittko F, Brandl M, Blecha S, Bein T, Apfelbacher C. Ambulatory and stationary healthcare use in survivors of ARDS during the first year after discharge from ICU: findings from the DACAPO cohort. Ann Intensive Care. 2019;9:70. https://doi.org/10.1186/s1361 3-019-0544-5.

25. Gayat E, Cariou A, Deye N, Vieillard-Baron A, Jaber S, Damoisel C, et al. Determinants of long-term outcome in ICU survivors: results from the FROG-ICU study. Crit Care. 2018;22:1276. https://doi.org/10.1186/s1305 4-017-1922-8.

26. Gaudry S, Messika J, Ricard J-D, Guillo S, Pasquet B, Dubief E, et al. Patient-important outcomes in randomized controlled trials in critically ill patients: a systematic review. Ann Intensive Care. 2017;7:28. https://doi. org/10.1186/s13613-017-0243-z.

27. Shah HA, Dritsaki M, Pink J, Petrou S. Psychometric properties of patient reported outcome measures (PROMs) in patients diagnosed with acute respiratory distress syndrome (ARDS). Health Qual Life Outcomes. 2016;14:15. https://doi.org/10.1186/s12955-016-0417-7.

28. Vargas M, Sutherasan Y, Brunetti I, Micalizzi C, Insorsi A, Ball L, et al. Mortality and long-term quality of life after percutaneous tracheotomy in Intensive Care Unit: a prospective observational study. Minerva Anestesiol. 2018;84:1024-31. https://doi.org/10.23736/S0375-9393.18.12133-X.

29. Mikkelsen ME, Christie JD, Lanken PN, Biester RC, Thompson BT, Bellamy $\mathrm{SL}$, et al. The adult respiratory distress syndrome cognitive outcomes study: long-term neuropsychological function in survivors of acute lung injury. Am J Respir Crit Care Med. 2012;185:1307-15. https://doi. org/10.1164/rccm.201111-20250C. 
30. Wade D, Hardy R, Howell D, Mythen M. Identifying clinical and acute psychological risk factors for PTSD after critical care: a systematic review. Minerva Anestesiol. 2013;79:944-63.

31. Bienvenu OJ, Colantuoni E, Mendez-Tellez PA, Dinglas VD, Shanholtz C, Husain N, et al. Depressive symptoms and impaired physical function after acute lung injury: a 2-year longitudinal study. Am J Respir Crit Care Med. 2012;185:517-24. https://doi.org/10.1164/rccm.201103-05030C.

32. Kamdar BB, Huang M, Dinglas VD, Colantuoni E, von Wachter TM, Hopkins $\mathrm{RO}$, Needham DM. Joblessness and lost earnings after acute respiratory distress syndrome in a 1-year national multicenter study. Am J Respir Crit Care Med. 2017;196:1012-20. https://doi.org/10.1164/rccm.20161 $1-23270 \mathrm{C}$.

33. Kamdar BB, Sepulveda KA, Chong A, Lord RK, Dinglas VD, Mendez-Tellez $P A$, et al. Return to work and lost earnings after acute respiratory distress syndrome: a 5-year prospective, longitudinal study of long-term survivors. Thorax. 2018;73:125-33. https://doi.org/10.1136/thoraxjnl-2017210217.

34. Freeman BD. Tracheostomy update: when and how. Crit Care Clin 2017;33:311-22. https://doi.org/10.1016/j.ccc.2016.12.007.

35. Freeman BD, Stwalley D, Lambert D, Edler J, Morris PE, Medvedev S, et al. High resource utilization does not affect mortality in acute respiratory failure patients managed with tracheostomy. Respir Care. 2013;58:186372. https://doi.org/10.4187/respcare.02359.

\section{Publisher's Note}

Springer Nature remains neutral with regard to jurisdictional claims in published maps and institutional affiliations.

\section{Submit your manuscript to a SpringerOpen ${ }^{\odot}$ journal and benefit from:}

- Convenient online submission

- Rigorous peer review

- Open access: articles freely available online

- High visibility within the field

- Retaining the copyright to your article

Submit your next manuscript at springeropen.com 